\title{
Blood Pressure Management for Acute Ischemic and Hemorrhagic Stroke: The Evidence
}

\author{
Sang-Bae Ko, MD, PhD ${ }^{1}$ Byung-Woo Yoon, MD, PhD, FAHA ${ }^{1}$ \\ ${ }^{1}$ Department of Neurology, Seoul National University Hospital, \\ Seoul, Republic of Korea \\ Semin Respir Crit Care Med 2017;38:718-725. \\ Address for correspondence Byung-Woo Yoon, MD, PhD, FAHA, \\ Department of Neurology, Seoul National University Hospital, 101 \\ Daehak-ro, Jongno-gu, Seoul 110-744, Republic of Korea \\ (e-mail: bwyoon@snu.ac.kr).
}

\begin{abstract}
Hypertension is the most common modifiable risk factor for stroke (both ischemic and hemorrhagic types). In the hyperacute phase, a majority of patients shows an elevated blood pressure (BP) at the time of presentation because of sympathetic hyperactivity or a physiological response to tissue ischemia. Therefore, BP may decrease spontaneously in a few hours and may drop further when complete recanalization is achieved. In stroke guidelines, an elevated BP is usually left untreated up to a systolic BP (SBP) of $220 \mathrm{~mm} \mathrm{Hg}$ and a diastolic BP of $120 \mathrm{~mm} \mathrm{Hg}$. This recommendation is based on the BP level that corresponds to the upper limit of the pressure autoregulation zone above which cerebral blood flow is directly dependent on BP. However, in patients in whom administration of recombinant tissue-type plasminogen activator is indicated, BP should be controlled to a level $<185 / 110 \mathrm{~mm} \mathrm{Hg}$ before infusion and should be maintained at levels $<180 / 105 \mathrm{~mm} \mathrm{Hg}$ to limit the risk of intracerebral hemorrhage (ICH). In cases where endovascular thrombectomy is considered, the optimal intra- and postprocedural BP target have not yet been clearly identified. Expert opinion recommends that intraprocedural BP reduction could be associated with a risk of poor outcomes, and therefore, SBP may be reduced only to 120 to $140 \mathrm{~mm} \mathrm{Hg}$ after successful reperfusion therapy. However, this recommendation is primarily based on observational studies and requires validation in prospective trials. It has been observed

\section{Keywords}

- blood pressure

- ischemic stroke

- intracerebral hemorrhage that in patients presenting with an $\mathrm{ICH}$, there is no perihematomal penumbra noted and rapid BP reduction is generally well tolerated without a risk of neurological worsening. Multiple trials describing acute reduction of BP recommend SBP reduction only to $140 \mathrm{~mm} \mathrm{Hg}$ because while there is no benefit of better functional outcomes below that level, there exists a definite risk of increased renal complications.
\end{abstract}

Hypertension (HT) is the most important modifiable risk factor for all types of stroke, ${ }^{1}$ although its effect is observed to be stronger in cases of intracerebral hemorrhage (ICH) compared with that in ischemic stroke. ${ }^{2}$ However, the effect of HT on stroke varies based on geographical regions. The INTERSTROKE study, based on evaluation of 13,000 stroke cases and 13,000 controls in 32 countries, has shown that the population attributable risk of HT for all types of stroke was higher in Southeast Asia (59.6\%) than that in Western Europe and North America (38.8\%) suggesting that HT is a more important risk factor in Asian countries than in the West. ${ }^{2}$

Regardless of prior history of HT, approximately 60 to $70 \%$ of stroke patients demonstrate a systolic blood pressure (SBP) $>140 \mathrm{~mm} \mathrm{Hg}$ on presentation, this proportion is higher in patients diagnosed with $\mathrm{ICH}^{3}$ A population-based study showed that SBP was substantially increased compared with premorbid levels and fell significantly within 24 hours in patients diagnosed with ICH. However, patients with ischemic
Issue Theme Advancements in Neurocritical Care and Emergency Neurology; Guest Editors: David Y. Hwang, MD, FNCS, and David M. Greer, MD, MA, FCCM, FAHA, FNCS, FAAN, FANA
Copyright (C 2017 by Thieme Medical Publishers, Inc., 333 Seventh Avenue, New York, NY 10001, USA. Tel: +1(212) 584-4662.
DOI https://doi.org/ $10.1055 / \mathrm{s}-0037-1608777$. ISSN 1069-3424. 
stroke showed only a mild elevation of BP. ${ }^{4}$ Among the different subtypes, lacunar stroke was associated with a higher level of BP than the levels associated with other subtypes. All these findings suggest that HT significantly affects small perforating vessels leading to lacunar infarcts or ICH.

It has been observed that an elevated BP may spontaneously decrease over a few days after presentation. ${ }^{5,6}$ A persistent elevation of BP is associated with cardiac complications, hemorrhagic transformation (HTF), hematoma expansion (HE), or enlargement of perihematomal edema-complications that are associated with poor functional outcomes. ${ }^{7-10}$ Therefore, although a certain degree of BP lowering might be required, the optimal target level and rapidity of BP reduction has not clearly been identified in patients with ischemic or hemorrhagic stroke. ${ }^{11,12}$ We present a review of current literature and summarize the goals of BP management in patients presenting with acute ischemic stroke and ICH.

\section{Hemodynamic Changes in Acute Stroke}

\section{Autoregulation}

Cerebral autoregulation (CA) is a mechanism that maintains constant cerebral blood flow (CBF) regardless of changes in cerebral perfusion pressure (CPP) or mean arterial pressure (MAP). ${ }^{13}$ When CA is intact, a drop in CPP may induce cerebral vasodilation via a decrease in vascular resistance to maintain constant CBF. ${ }^{14}$ Real-time assessment of this dynamic mechanism of CA may require sophisticated tools for multimodality neuromonitoring. ${ }^{15}$ However, in real-world clinical practice, it is difficult to assess the status of CA in stroke patients without continuous monitoring. Based on studies performed in patients with severe traumatic brain injury, we extrapolate that CA failure might contribute to further brain injury in stroke patients and that its severity is directly proportional to stroke severity. ${ }^{16}$ It can be hypothesized that a certain degree of impairment in CA exists in patients with severe stroke. ${ }^{17}$

When the MAP ranges between 50 and $150 \mathrm{~mm} \mathrm{Hg}$, a stable CBF is maintained if CA is intact. ${ }^{18,19}$ An increase in MAP $>150 \mathrm{~mm} \mathrm{Hg}$ may lead to forced dilation of cerebral blood vessels and cerebral hyperperfusion in the autoregulatory breakthrough zone. ${ }^{15}$ On the contrary, a drop in MAP to $<50 \mathrm{~mm} \mathrm{Hg}$ results in a passive collapse of blood vessels and leads to ischemia secondary to hypoperfusion. CA is known to be altered/defective in patients presenting with severe stroke; therefore, an abrupt BP drop in such patients could lead to a concomitant decrease in $\mathrm{CBF}$, which may predispose them to secondary cerebral ischemia.

\section{Acute Ischemic Stroke}

\section{Mechanisms of Blood Pressure Elevation}

Elevated BP is commonly observed in patients presenting with acute ischemic stroke, especially in a setting of a prior history of $\mathrm{HT}^{3,20,21}$ An exact pathomechanism to explain the BP elevation remains unclear. However, proposed pathomechanisms are a stress response secondary to sympathetic hyperactivity, disturbed parasympathetic activity, elevated levels of circulating catecholamines or brain natriuretic peptide, tissue ischemia, or a combination of the above factors. ${ }^{3,22-24}$ In patients demonstrating large vessel occlusion, an elevated BP may return to baseline level following complete recanalization, suggesting that BP elevation is closely linked to brain tissue ischemia. ${ }^{25}$ Therefore, BP elevation by itself might be beneficial in augmenting $\mathrm{CBF}$ in the penumbra in patients with ischemic stroke. Clinical data combined with perfusion imaging have shown that a relative filling delay decreases as the BP increases, suggesting the augmentation of cerebral perfusion via leptomeningeal collaterals. ${ }^{26}$ To summarize, the BP surge observed in cases of acute ischemic infarction may be a natural response to tissue ischemia.

\section{American Stroke Society Guideline Suggestion}

Guidelines suggest that a level of $220 / 120 \mathrm{~mm} \mathrm{Hg}$, which is the upper limit of BP corresponding to adequate function of $\mathrm{CA}$, is usually considered an acceptable level of BP elevation. BP elevation beyond this level might be associated with hyperperfusion syndrome or HTF in the ischemic tissue. As mentioned earlier, the reference range of intact $C A$ is a MAP between 50 and $150 \mathrm{~mm} \mathrm{Hg}$. The recommended BP level of 220/120 mm Hg can based off of a MAP of $150 \mathrm{~mm} \mathrm{Hg}{ }^{27}$

\section{Points to Consider with Use of Intravenous Thrombolysis}

Symptomatic ICH must be recognized as the most serious complication when considering infusion of recombinant tissue-type plasminogen activator (tPA) ( - Fig. 1). When administration of tPA is considered, BP should be controlled to a level $<185 / 100 \mathrm{~mm} \mathrm{Hg}$ and should be maintained at a level $<180 / 105 \mathrm{~mm} \mathrm{Hg}$ even after completion of infusion. ${ }^{28,29}$ In a pilot dose-finding study performed in patients with ischemic stroke, based on a previous study examining administration of tPA in patients with myocardial infarction, the original exclusion criterion of BP elevation was a level of 200/120 mm Hg. However, three patients demonstrated symptomatic ICH in the high-dose tier $(0.95-1.08 \mathrm{mg} / \mathrm{kg}),{ }^{30}$ and all patients showed BP level $>160 / 90 \mathrm{~mm} \mathrm{Hg}$, while $38 \%$ (27 of 71) patients without ICH showed BP > 160/90 mm Hg. Therefore, the protocol was amended to exclude patients with MAP $>133 \mathrm{~mm} \mathrm{Hg}$, which could be interpreted as a BP reading of $185 / 110 \mathrm{~mm} \mathrm{Hg}{ }^{30}$ Subsequent analysis showed that the dose of infused tPA and the level of DBP were significantly associated with ICH after intravenous (IV) thrombolysis. ${ }^{31}$ Following these findings, strict BP control was recommended in patients who were administered tPA.

Some patients may need antihypertensive drugs to maintain $\mathrm{BP}<185 / 110 \mathrm{~mm}$ Hg for safe administration of tPA infusion. The aforementioned study showed that $B P$ reduction to initiate tPA treatment does not affect adverse outcomes in patients with ischemic stroke. A substudy from tPA National Institute of Neurological Disorders and Stroke (NINDS) trial showed that antihypertensive therapy administered prior to tPA was not associated with differences in early or late outcomes. ${ }^{32}$ In addition, another study performed by independent investigators showed that antihypertensive treatment prior to tPA infusion was not independently associated with poor neurological outcomes. ${ }^{33}$ Among the 427 patients studied, 89 received 


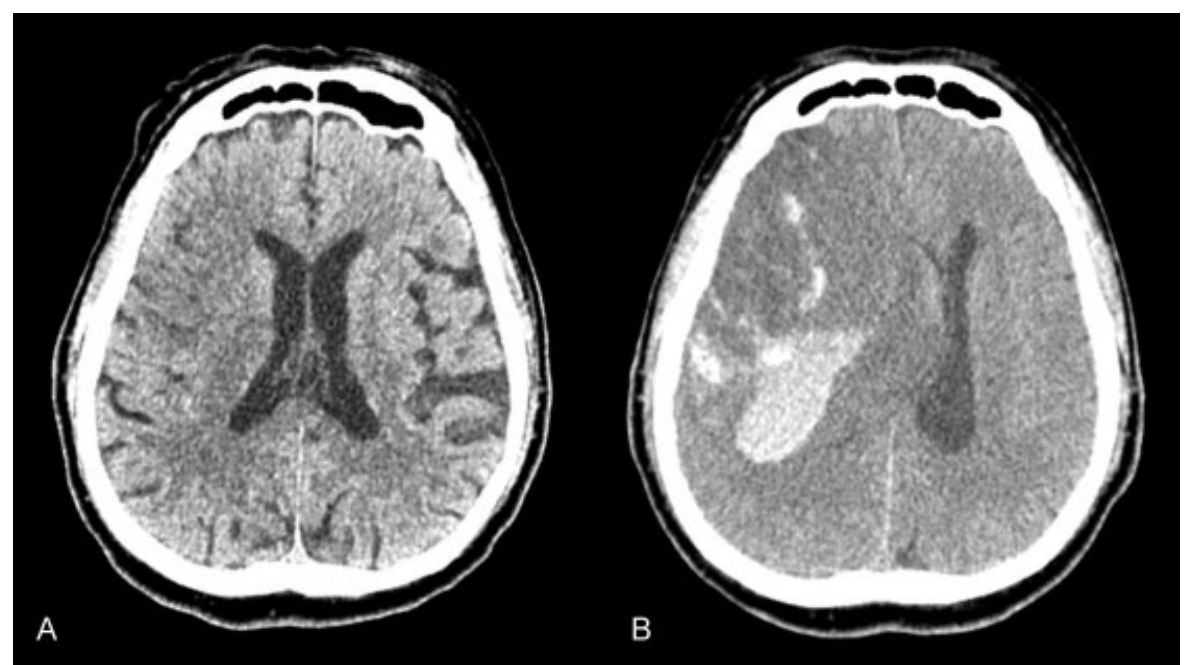

Fig. 1 Brain CT in a patient who experienced a significant symptomatic intracerebral hemorrhage after recombinant tPA. A 68-year-old patient was presented with left side hemiparesis. NIHSS was 11, and brain CT showed subtle hypoattenuation in the right frontal lobe (Panel A). tPA was administered 3.5 hours after symptom onset. Blood pressure was strictly maintained below 180/105 mm $\mathrm{Hg}$. Five hours after tPA infusion, this patient suddenly became somnolent, and follow-up brain CT showed a symptomatic parenchymal hematoma with midline shifting (Panel B). CT, computed tomography; NIHSS, National Institutes of Health Stroke Scale; tPA, tissue-type plasminogen activator.

aggressive BP control prior to thrombolysis, 65 received standard BP control, and 273 required no BP control. Although patients requiring BP control scored higher on the National Institutes of Health Stroke Scale (NIHSS), BP reduction was not associated with adverse events after adjusting for baseline characteristics. Therefore, careful attention to and gentle management of BP are warranted in patients presenting with stroke who are considered candidates suitable for tPA treatment.

The Safe Implementation of Thrombolysis in Stroke-International Stroke Thrombolysis Register (SITS-ISTR) is a prospective multinational register containing data of patients treated with thrombolysis following an acute ischemic stroke. Secondary analysis of data from this monitoring registry has shown that persistently high SBP up to 24 hours after thrombolysis was associated with worse outcomes. ${ }^{34}$ Moreover, the relationship between SBP and outcomes showed a U-shaped association suggesting that a higher proportion of patients with SBP 141 to $150 \mathrm{~mm} \mathrm{Hg}$ demonstrated favorable outcomes defined as a modified Rankin scale (mRS) of 0 to 2 at 3 months. ${ }^{34}$ Considering that the SITS-ISTR registry is not a randomized trial, these results are inconclusive, and we can only hypothesize regarding the findings.

The Enhanced Control of Hypertension and Thrombolysis Stroke Study was originally designed to compare two doses of tPA ( 0.6 vs. $0.9 \mathrm{mg} / \mathrm{kg})$. In this trial, patients with elevated SBP (150-220 $\mathrm{mm} \mathrm{Hg}$ ) were randomly assigned to an intensive BP-lowering group (SBP $<140 \mathrm{~mm} \mathrm{Hg}$ within 1 hour) and a conventional guideline group (SBP $<180 \mathrm{~mm} \mathrm{Hg}$ ). ${ }^{35}$ Choice of antihypertensive used was at the discretion of the treating physicians. The primary outcome regarding tPA dose has already been published; however, data from different $\mathrm{BP}$ targets continue and are scheduled to be completed in $2018 .{ }^{36}$ Results of this trial may provide an answer regarding the optimal target BP that needs to be achieved after IV thrombolysis.

\section{Endovascular Thrombectomy}

No strong data exist regarding target BP after endovascular thrombectomy (EVT). A study involving 674 patients who underwent IV or intra-arterial thrombolysis showed that a $J$-shaped relationship was identified in terms of the association between BP over the first 24 hours and functional outcomes in patients who failed recanalization, whereas a linear correlation was identified in terms of the association between BP and functional outcome in patients who demonstrated complete recanalization. These findings suggest that recanalization status should be considered an important modifier of neurological outcomes. ${ }^{37}$

Intraprocedural BP drop might be detrimental in patients who undergo EVT. Earlier studies focusing on the type of anesthesia show that general anesthesia (GA) was inferior to conscious sedation (CS) in terms of neurological outcomes in patients presenting with acute large vessel occlusion. ${ }^{38,39}$ However, it is unclear whether anesthesia itself or the ensuing drop in BP was the cause of this finding; most patients who received GA showed a lower BP during EVT. ${ }^{40}$ Low BP during an EVT procedure is considered to be an important contributor to poor functional outcomes. ${ }^{40,41}$ A subsequent study comparing GA and CS has since shown that the two anesthesia methods are equivalent in terms of functional outcomes. ${ }^{42}$ That study utilized strict protocols to maintain target SBP between 140 and $150 \mathrm{~mm}$ $\mathrm{Hg}$ with variability in BP maintained at $<10 \mathrm{~mm} \mathrm{Hg.}{ }^{42}$ Based on these results, it can be deduced that a very low $\mathrm{BP}$ in nonrecanalized patients might be harmful when undergoing EVT. However, the optimal intraprocedural target BP level has not yet been established. Expert opinions vary with some authors recommending a level of approximately 140 to $160 \mathrm{~mm} \mathrm{Hg}$ and others recommending a level of 120 to $140 \mathrm{~mm} \mathrm{Hg} .{ }^{43,44}$ 
Moreover, the optimal target BP after complete recanalization has not yet been conclusively established/defined. Modest BP control might be helpful in reducing reperfusion injury or HTF. In a retrospective study that included 228 patients who showed complete recanalization after EVT, patients were categorized into three groups (those without HFT, those with asymptomatic HTF, and those with symptomatic HTF), and mean SBP was compared between these groups. It was observed that patients without HFT showed lower SBP (mean $159 \mathrm{~mm} \mathrm{Hg}$ ) compared with those with asymptomatic HTF (mean SBP $169 \mathrm{~mm} \mathrm{Hg}$ ) and symptomatic HTF (mean SBP $170 \mathrm{~mm} \mathrm{Hg}$ ) suggesting that lower BP might be associated with a lower risk for $\mathrm{HTF}^{45}$ Another study has shown that the BP level after EVT was one of the factors related to functional outcomes at 3 months. Patients with moderate BP control (SBP $<160 \mathrm{~mm} \mathrm{Hg}$ ) showed lower odds for mortality at 3 months than those with permissive HT (SBP $<220$ or $<180 \mathrm{~mm} \mathrm{Hg}$ in cases warranting IV administration of tPA). ${ }^{46}$ To summarize, it can be stated that modest BP control might be needed in patients with complete recanalization following EVT, although the optimal target SBP that needs to be achieved warrants further investigation for a definitive answer.

\section{Blood Pressure Variability}

In addition to absolute BP levels, variability of BP levels may be an independent predictor for poor clinical outcomes. Marked BP variability measured as significant differences in successive variation was shown to be associated with poor functional outcomes (mRS of 3-6), higher rate of mortality, and symptomatic ICH in stroke patients treated with IV tPA. ${ }^{47,48}$

\section{Blood Pressure Control in a Nonthrombolysis Setting}

Several observational studies have examined the relationship between BP and outcomes in nonthrombolysis settings. A post hoc analysis of the International Stroke Trial reported that SBP measured immediately after randomization was associated with poor functional outcomes and mortality in 17,398 patients with acute ischemic stroke. The association showed a U-shaped relationship, and SBP of 140 to $179 \mathrm{~mm} \mathrm{Hg}$ (a nadir at $\sim 150 \mathrm{~mm}$ $\mathrm{Hg}$ ) was associated with the best outcome. ${ }^{49}$ A U-shaped relationship has also been demonstrated in another independent study. ${ }^{5}$ However, these studies did not focus on the effect of treatment with antihypertensive agents.

Several clinical trials have focused on modulation of BP within several days after onset of an ischemic stroke. ${ }^{50-54}$ The Acute Candesartan Cilexetil Therapy in Stroke Survivors (ACCESS) trial was designed to assess the outcomes of modest $\mathrm{BP}$ reduction following administration of candesartan in 342 patients with elevated BP (defined as BP $>220 / 110 \mathrm{~mm} \mathrm{Hg}$ within 24 hours after admission or $>180 / 105 \mathrm{~mm} \mathrm{Hg}$ between 24 and 36 hours after admission). Candesartan was administered for 7 days after which the BP profile was reviewed. When mean BP was $>135 / 85 \mathrm{~mm} \mathrm{Hg}$, candesartan was continued.$^{50}$ Results showed that early use of candesartan after onset of an ischemic stroke significantly improved cardiovascular mortality and morbidity. A subsequent study involving a larger number of patients was performed to validate these results. ${ }^{51}$ The Scandinavian Candesartan Acute Stroke Trial was a phase III clinical trial that included 2,029 patients using study protocols that were very similar to the ACCESS trial. However, functional outcomes were not different in patients with or without candesartan treatment. Moreover, patients who were treated with candesartan showed less favorable outcomes at 6 months compared with those who received a placebo. Interestingly, $15 \%$ of the included patients were those diagnosed with a hemorrhagic stroke. However, subgroup analysis did not show any benefit even in patients with a hemorrhagic stroke. Moreover, acute BP management using valsartan showed a negative effect on functional outcomes. The Valsartan Efficacy oN modesT blood pressUre REduction in acute ischemic stroke trial included 393 patients diagnosed with acute ischemic stroke within 48 hours and showed that early BP lowering was significantly associated with a higher risk for early neurological deterioration. ${ }^{55}$ Based on these findings, it can be stated that if BP reduction is a risk factor for poor neurological outcomes, discontinuing the use of antihypertensive agents might be considered in patients with acute ischemic stroke who are currently administered antihypertensives.

The Continue Or Stop post-Stroke Antihypertensives Collaborative Study (COSSACS) trial compared the effect of continuing or stopping antihypertensive drugs for 2 weeks on functional outcomes. The study included 763 patients and continuation of antihypertensives lowered SBP and DBP by 13 and $8 \mathrm{~mm} \mathrm{Hg}$, respectively. However, this trial could not conclusively demonstrate the differences in outcomes between the groups probably because of the small number of patients included. ${ }^{54}$ The most recent trial that studied the effect of BP lowering was the China Antihypertensive Trial in Acute Ischemic Stroke (CATIS) trial. This study enrolled 4,071 patients with acute ischemic stroke within 48 hours and in whom SBP was measured between 140 and $220 \mathrm{~mm} \mathrm{Hg}$. Compared with the placebo group, the active BP lowering group (SBP lowering by $10-25 \%$ within a day) did not show benefit in terms of neurological disability at 14 days. ${ }^{52}$ Based on these clinical trials, a meta-analysis was performed and concluded that early management of BP in acute ischemic stroke was not associated with better clinical outcomes. ${ }^{56}$

\section{Brain Edema and Blood Pressure}

Brain edema is one of the major complications known to occur after an acute ischemic stroke. Significant brain edema leads to brain tissue herniation secondary to an elevation in intracranial pressure and subsequent poor neurological outcomes. Cytotoxic edema develops due to energy failure within the first few hours after permanent ischemia and is followed by the development of ionic edema owing to disruption of the osmotic pressure gradient. Vasogenic edema begins to develop a few days later due to the breakdown of the blood-brain barrier (BBB), which is linked to $\mathrm{HTF}^{57}$ In brain tissues with BBB breakdown, hyperperfusion or HT is mechanistically associated with brain edema and $\mathrm{HTF}^{58}$ A study has shown that higher SBP was associated with brain edema in patients with acute ischemic and hemorrhagic stroke, which is in agreement with the afore-mentioned statement. ${ }^{59}$ Moreover, patients with brain edema showed persistently elevated SBP 
compared with those without brain edema and usually had a spontaneous decline in SBP over time. ${ }^{59}$

A study has investigated the association between BP variability and brain edema. Among the included patients, 75.8\% had presented with ischemic strokes. Development of brain edema was significantly associated with stroke severity and BP variability measured as "time rate" implying the rapidity of SBP change, while the absolute SBP failed to show a statistically significant relationship with brain edema. ${ }^{60} \mathrm{~A}$ time rate of BP variation of $0.1 \mathrm{~mm} \mathrm{Hg} / \mathrm{min}$ was significantly associated with a $13.9 \%$ increased probability of developing brain swelling.

\section{Hemorrhagic Transformation}

HTF develops in approximately 10 to $15 \%$ of cases of ischemic stroke and is associated with poor functional outcomes. ${ }^{61}$ When HTF produces a mass effect, it leads to symptoms in the patient and is related with neurological deterioration. A high $\mathrm{BP}$ has been recognized as a risk factor for $\mathrm{HTF}^{62}$ Moreover, wide fluctuations in BP plays a role in development of HTF. ${ }^{63}$ SBP variability and successive variation of SBP were associated with HTF in patients who underwent IV thrombolysis. ${ }^{63}$

\section{Hemodynamic Stroke with Low Perfusion}

In animals, therapeutic approaches targeting enhancement of collateral circulation have shown better functional outcomes without significant complications. ${ }^{64}$ Those approaches include induced HT using phenylephrine (PE) infusion, intravascular volume expansion, cerebral arteriolar vasodilation, or $\mathrm{CBF}$ version using a head-down tilt. A study has investigated the effect of norepinephrine (NE) administration in patients with acute ischemic stroke within 24 hours from symptom onset. These patients presented with an NIHSS score $\geq 5$ on admission, SBP $\leq 140 \mathrm{~mm} \mathrm{Hg}$ before initiation of infusion, and without clinical signs of hypovolemia or other treatable causes for low blood pressure. Continuous infusion of NE was performed in 34 patients, targeting an SBP $>10 \%$ from baseline. After 12 hours of infusion, NE infusion was tapered, and BP returned to the baseline level. ${ }^{65}$ Based on this study, shortterm NE infusion was observed to be a feasible treatment option without a significantly increased risk of complications including ICH or cardiac arrhythmia. In another study, PE administration was used to increase SBP by $20 \%$. Functional outcome assessment was not possible because the number of patients included in the study was very small $(n=13) .{ }^{66}$ Another study has investigated the effect of NE-infusioninduced HT wherein surrogate markers such as mean flow velocity were calculated using transcranial Doppler ultrasound. It was observed that NE-infusion-induced HT augmented mean Doppler flow velocities with concomitant elevation of intracranial pressure. ${ }^{67}$ However, to date, no high-quality randomized clinical trial has recommended the utility of catecholamine-induced HT in hemodynamic stroke.

\section{Intracerebral Hemorrhage}

Hematoma Expansion in Intracerebral Hemorrhage HT plays a more significant role in ICH compared with its effect in ischemic stroke. ${ }^{2}$ In addition to initial hemorrhage volume,
HE is closely related with poor functional outcomes. ${ }^{15,68} \mathrm{HE}$ is defined as an increased ICH volume by $33 \%$ from the baseline and is reported in approximately up to $38 \%$ of patients within the first 24 hours of symptom onset. ${ }^{69}$ Considering that the driving force of hemorrhage is hydrostatic pressure, BP reduction might be mechanistically helpful in reducing the risk of HE. Several nonrandomized observational studies have shown a possible benefit of $\mathrm{BP}$ reduction in patients with $\mathrm{ICH}^{70,71}$ The concern associated with disproportionate BP lowering is precipitation of ischemia in the perihematomal area. However, several neuroimaging studies using positron emission tomography have shown that global or perihematomal CBF does not change significantly even with a $15 \%$ reduction in MAP, suggesting that CA is relatively intact in patients with small $\mathrm{ICH}^{72}$

Another study used CT perfusion to assess possible CBF changes in perihematomal tissue in patients with ICH. The ICH Acutely Decreasing Arterial Pressure Trial included 75 patients and randomized them into two groups (SBP $<150 \mathrm{~mm} \mathrm{Hg}$ and $\mathrm{SBP}<180 \mathrm{~mm} \mathrm{Hg}$ ). CT perfusion was performed 2 hours after randomization and showed that perihematomal $\mathrm{CBF}$ was lower compared with the contralateral homologous region and that rapid reduction in $\mathrm{BP}$ did not decrease perihematomal $\mathrm{CBF}$, suggesting that there is no penumbra in the perihematomal area. ${ }^{73}$ Several clinical trials have been performed to verify the safety and efficacy of BP reduction in patients with $\mathrm{ICH} .^{74-77}$

\section{Clinical Trials}

The Antihypertensive Treatment of Acute Cerebral Hemorrhage (ATACH) study was a feasibility trial using IV nicardipine in 60 patients with acute $\mathrm{ICH}$. The results showed that acute BP reduction to 110 to $140 \mathrm{~mm} \mathrm{Hg}$ was relatively safe. ${ }^{76}$ Although the neurological deterioration rate was higher in the intensive therapy group (target SBP of $110-140 \mathrm{~mm} \mathrm{Hg}$ ) than in the group with a target SBP of $140-170 \mathrm{~mm} \mathrm{Hg}$ (tier 2) and the group with a target SBP of 170 to $200 \mathrm{~mm} \mathrm{Hg}$ (tier 1), there was no temporal relationship observed between the infusion of IV nicardipine and the time of onset of neurological deterioration.

The Intensive Blood Pressure Reduction in Acute Cerebral Hemorrhage Trial (INTERACT) compared the effect of BP lowering on HE. ${ }^{75}$ The 404 patients included in the trial were randomized to an intensive BP lowering group (target $\mathrm{SBP}<140 \mathrm{~mm} \mathrm{Hg}$ within 6 hours) and a guideline-based BP lowering group (SBP $<180 \mathrm{~mm} \mathrm{Hg}$ ). Results showed that intensive BP lowering produced a less proportional increase in hematoma volume. However, this trial was underpowered to show clinical benefit. The subsequent INTERACT2 trial involving 2,839 patients showed that intensive lowering of BP did not lead to significant reduction in poor functional outcomes or mortality, although a secondary outcome parameter using ordinal mRS analysis showed that intensive treatment was associated with better functional outcomes. ${ }^{74}$

The ATACH-2 trial compared the effect of intensive BP reduction (SBP of $110-139 \mathrm{~mm} \mathrm{Hg}$ ) and modest $\mathrm{BP}$ reduction (SBP of $140-179 \mathrm{~mm} \mathrm{Hg}$ ) on functional outcomes in 1,000 patients with acute $\mathrm{ICH}^{77}$ The majority of patients included demonstrated ICH in the basal ganglia and thalamus. Rapid BP reduction was attempted within 4.5 hours from stroke onset 
and maintained over the initial 24 hours of presentation using IV nicardipine infusion. The mean minimum SBP in the first 2 hours was observed to be $128.9 \mathrm{~mm} \mathrm{Hg}$ (intensive group) and $141.1 \mathrm{~mm} \mathrm{Hg}$ (standard treatment group), respectively. Results of the ATACH-2 trial show that intensive BP reduction to $<140 \mathrm{~mm} \mathrm{Hg}$ (median $120 \mathrm{~mm} \mathrm{Hg}$ ) was not superior to maintaining an SBP of $>140 \mathrm{~mm} \mathrm{Hg}$ (median $140 \mathrm{~mm} \mathrm{Hg}$ ) in terms of the proportion of mRS of 4 to 6 noted at 3 months and the rate of HE noted at 24 hours. In addition, the intensive BP reduction group showed a 2.3 -fold higher incidence of adverse renal events than the standard group. Therefore, SBP reduction to a level $<140 \mathrm{~mm} \mathrm{Hg}$ is not recommended because while aggressive BP reduction was not observed to be effective in improving functional outcomes, it did increase the risk of renal complications.

\section{Conclusion}

BP elevation is commonly associated with acute stroke and may be transient and may spontaneously decrease within several hours after presentation. The optimal target BP should be individualized based on the patient's condition including stroke subtypes and treatment-related issues, such as thrombolytic modalities employed and recanalization status. For acute ICH, an SBP reduction to a level $<140 \mathrm{~mm}$ $\mathrm{Hg}$ is not necessarily recommended across the board.

\section{References}

1 James PA, Oparil S, Carter BL, et al. 2014 evidence-based guideline for the management of high blood pressure in adults: report from the panel members appointed to the Eighth Joint National Committee (JNC 8). JAMA 2014;311(05):507-520

2 O'Donnell MJ, Chin SL, Rangarajan S, et al; INTERSTROKE investigators. Global and regional effects of potentially modifiable risk factors associated with acute stroke in 32 countries (INTERSTROKE): a case-control study. Lancet 2016;388(10046):761-775

3 Qureshi AI, Ezzeddine MA, Nasar A, et al. Prevalence of elevated blood pressure in 563,704 adult patients with stroke presenting to the ED in the United States. Am J Emerg Med 2007;25(01):32-38

4 Fischer U, Cooney MT, Bull LM, et al. Acute post-stroke blood pressure relative to premorbid levels in intracerebral haemorrhage versus major ischaemic stroke: a population-based study. Lancet Neurol 2014;13(04):374-384

5 Vemmos KN, Tsivgoulis G, Spengos K, et al. Blood pressure course in acute ischaemic stroke in relation to stroke subtype. Blood Press Monit 2004;9(03):107-114

6 Wallace JD, Levy LL. Blood pressure after stroke. JAMA 1981;246 (19):2177-2180

7 Ko Y, Park JH, Yang MH, et al. The significance of blood pressure variability for the development of hemorrhagic transformation in acute ischemic stroke. Stroke 2010;41(11):2512-2518

8 Willmot M, Leonardi-Bee J, Bath PM. High blood pressure in acute stroke and subsequent outcome: a systematic review. Hypertension 2004;43(01):18-24

9 Fagan SC, Bowes MP, Lyden PD, Zivin JA. Acute hypertension promotes hemorrhagic transformation in a rabbit embolic stroke model: effect of labetalol. Exp Neurol 1998;150(01):153-158

10 Qureshi AI. Acute hypertensive response in patients with stroke: pathophysiology and management. Circulation 2008;118(02): 176-187

11 Hong KS. Blood pressure management for stroke prevention and in acute stroke. J Stroke 2017;19(02):152-165
12 McManus M, Liebeskind DS. Blood pressure in acute ischemic stroke. J Clin Neurol 2016;12(02):137-146

13 Jordan JD, Powers WJ. Cerebral autoregulation and acute ischemic stroke. Am J Hypertens 2012;25(09):946-950

14 Powers WJ, Videen TO, Diringer MN, Aiyagari V, Zazulia AR. Autoregulation after ischaemic stroke. J Hypertens 2009;27 (11):2218-2222

15 Ko SB, Choi HA, Parikh G, et al. Multimodality monitoring for cerebral perfusion pressure optimization in comatose patients with intracerebral hemorrhage. Stroke 2011;42(11):3087-3092

16 Aries MJ, Czosnyka M, Budohoski KP, et al. Continuous determination of optimal cerebral perfusion pressure in traumatic brain injury. Crit Care Med 2012;40(08):2456-2463

17 Bösel J. Blood pressure control for acute severe ischemic and hemorrhagic stroke. Curr Opin Crit Care 2017;23(02):81-86

18 Rivera-Lara L, Zorrilla-Vaca A, Geocadin RG, Healy RJ, Ziai W, Mirski MA. Cerebral autoregulation-oriented therapy at the bedside: a comprehensive review. Anesthesiology 2017;126(06):1187-1199

19 Xiong L, Liu X, Shang T, et al. Impaired cerebral autoregulation: measurement and application to stroke. J Neurol Neurosurg Psychiatry 2017;88(06):520-531

20 AlSibai A, Qureshi AI. Management of acute hypertensive response in patients with ischemic stroke. Neurohospitalist 2016; 6(03):122-129

21 Britton M, Carlsson A, de Faire U. Blood pressure course in patients with acute stroke and matched controls. Stroke 1986;17(05):861-864

22 Myers MG, Norris JW, Hachniski VC, Sole MJ. Plasma norepinephrine in stroke. Stroke 1981;12(02):200-204

23 Nakagawa K, Yamaguchi T, Seida M, et al. Plasma concentrations of brain natriuretic peptide in patients with acute ischemic stroke. Cerebrovasc Dis 2005;19(03):157-164

24 Brosnan MJ, Clark JS, Jeffs B, et al. Genes encoding atrial and brain natriuretic peptides as candidates for sensitivity to brain ischemia in stroke-prone hypertensive rats. Hypertension 1999; 33(1 Pt 2):290-297

25 John S, Hazaa W, Uchino K, Hussain MS. Timeline of blood pressure changes after intra-arterial therapy for acute ischemic stroke based on recanalization status. J Neurointerv Surg 2017;9 (05):455-458

26 Jiang B, Churilov L, Kanesan L, et al. Blood pressure may be associated with arterial collateralization in anterior circulation ischemic stroke before acute reperfusion therapy. J Stroke 2017; 19(02):222-228

27 Jauch EC, Saver JL, Adams HP Jr, et al; American Heart Association Stroke Council; Council on Cardiovascular Nursing; Council on Peripheral Vascular Disease; Council on Clinical Cardiology. Guidelines for the early management of patients with acute ischemic stroke: a guideline for healthcare professionals from the American Heart Association/American Stroke Association. Stroke 2013;44(03):870-947

28 National Institute of Neurological Disorders and Stroke rt-PA Stroke Study Group. Tissue plasminogen activator for acute ischemic stroke. N Engl J Med 1995;333(24):1581-1587

29 Demaerschalk BM, Kleindorfer DO, Adeoye OM, et al; American Heart Association Stroke Council and Council on Epidemiology and Prevention. Scientific rationale for the inclusion and exclusion criteria for intravenous alteplase in acute ischemic stroke: a statement for healthcare professionals from the American Heart Association/American Stroke Association. Stroke 2016;47(02):581-641

30 Brott TG, Haley EC Jr, Levy DE, et al. Urgent therapy for stroke. Part I. Pilot study of tissue plasminogen activator administered within 90 minutes. Stroke 1992;23(05):632-640

31 Levy DE, Brott TG, Haley EC Jr, et al. Factors related to intracranial hematoma formation in patients receiving tissue-type plasminogen activator for acute ischemic stroke. Stroke 1994;25(02): 291-297

32 Brott T, Lu M, Kothari R, et al. Hypertension and its treatment in the NINDS rt-PA Stroke Trial. Stroke 1998;29(08):1504-1509 
33 Darger B, Gonzales N, Banuelos RC, Peng H, Radecki RP, Doshi PB. Outcomes of patients requiring blood pressure control before thrombolysis with tPA for acute ischemic stroke. West J Emerg Med 2015;16(07):1002-1006

34 Ahmed N, Wahlgren N, Brainin M, et al; SITS Investigators. Relationship of blood pressure, antihypertensive therapy, and outcome in ischemic stroke treated with intravenous thrombolysis: retrospective analysis from Safe Implementation of Thrombolysis in Stroke-International Stroke Thrombolysis Register (SITS-ISTR). Stroke 2009;40(07):2442-2449

35 Huang Y, Sharma VK, Robinson T, et al; ENCHANTED investigators. Rationale, design, and progress of the ENhanced Control of Hypertension ANd Thrombolysis strokE stuDy (ENCHANTED) trial: an international multicenter $2 \times 2$ quasi-factorial randomized controlled trial of low- vs. standard-dose rt-PA and early intensive vs. guideline-recommended blood pressure lowering in patients with acute ischaemic stroke eligible for thrombolysis treatment. Int J Stroke 2015;10(05):778-788

36 Anderson CS, Robinson T, Lindley RI, et al; ENCHANTED Investigators and Coordinators. Low-dose versus standard-dose intravenous alteplase in acute ischemic stroke. N Engl J Med 2016;374 (24):2313-2323

37 Martins AI, Sargento-Freitas J, Silva F, et al. Recanalization modulates association between blood pressure and functional outcome in acute ischemic stroke. Stroke 2016;47(06):1571-1576

38 Davis MJ, Menon BK, Baghirzada LB, et al; Calgary Stroke Program. Anesthetic management and outcome in patients during endovascular therapy for acute stroke. Anesthesiology 2012;116(02):396-405

39 Brinjikji W, Murad MH, Rabinstein AA, Cloft HJ, Lanzino G, Kallmes DF. Conscious sedation versus general anesthesia during endovascular acute ischemic stroke treatment: a systematic review and meta-analysis. AJNR Am J Neuroradiol 2015;36(03):525-529

40 Treurniet KM, Berkhemer OA, Immink RV, et al; MR CLEAN investigators. A decrease in blood pressure is associated with unfavorable outcome in patients undergoing thrombectomy under general anesthesia. J Neurointerv Surg 2017; pii:neurintsurg2017-012988

41 John S, Hazaa W, Uchino K, et al. Lower intraprocedural systolic blood pressure predicts good outcome in patients undergoing endovascular therapy for acute ischemic stroke. Interv Neurol 2016;4(3-4):151-157

42 Schönenberger S, Uhlmann L, Hacke W, et al. Effect of conscious sedation vs general anesthesia on early neurological improvement among patients with ischemic stroke undergoing endovascular thrombectomy: a randomized clinical trial. JAMA 2016;316 (19):1986-1996

43 Al-Mufti F, Dancour E, Amuluru K, et al. Neurocritical care of emergent large-vessel occlusion: the era of a new standard of care. J Intensive Care Med 2017;32(06):373-386

44 Bösel J. Intensive care management of the endovascular stroke patient. Semin Neurol 2016;36(06):520-530

45 Mistry EA, Mistry AM, Nakawah MO, et al. Systolic blood pressure within 24 hours after thrombectomy for acute ischemic stroke correlates with outcome. J Am Heart Assoc 2017;6(05):e006167

46 Goyal N, Tsivgoulis G, Pandhi A, et al. Blood pressure levels post mechanical thrombectomy and outcomes in large vessel occlusion strokes. Neurology 2017;89(06):540-547

47 de Havenon A, Bennett A, Stoddard GJ, et al. Increased blood pressure variability is associated with worse neurologic outcome in acute anterior circulation ischemic stroke. Stroke Res Treat 2016;2016:7670161

48 Kellert L, Hametner C, Ahmed N, et al; SITS Investigators. Reciprocal interaction of 24-hour blood pressure variability and systolic blood pressure on outcome in stroke thrombolysis. Stroke 2017;48(07):1827-1834

49 Leonardi-Bee J, Bath PM, Phillips SJ, Sandercock PA; IST Collaborative Group. Blood pressure and clinical outcomes in the International Stroke Trial. Stroke 2002;33(05):1315-1320
50 Schrader J, Lüders S, Kulschewski A, et al; Acute Candesartan Cilexetil Therapy in Stroke Survivors Study Group. The ACCESS study: evaluation of Acute Candesartan Cilexetil Therapy in Stroke Survivors. Stroke 2003;34(07):1699-1703

51 Sandset EC, Bath PM, Boysen G, et al; SCAST Study Group. The angiotensin-receptor blocker candesartan for treatment of acute stroke (SCAST): a randomised, placebo-controlled, double-blind trial. Lancet 2011;377(9767):741-750

52 He J, Zhang Y, Xu T, et al; CATIS Investigators. Effects of immediate blood pressure reduction on death and major disability in patients with acute ischemic stroke: the CATIS randomized clinical trial. JAMA 2014;311(05):479-489

53 Potter JF, Robinson TG, Ford GA, et al. Controlling hypertension and hypotension immediately post-stroke (CHHIPS): a randomised, placebo-controlled, double-blind pilot trial. Lancet Neurol 2009;8(01):48-56

54 Robinson TG, Potter JF, Ford GA, et al; COSSACS Investigators. Effects of antihypertensive treatment after acute stroke in the Continue or Stop Post-Stroke Antihypertensives Collaborative Study (COSSACS): a prospective, randomised, open, blinded-endpoint trial. Lancet Neurol 2010;9(08):767-775

55 Oh MS, Yu KH, Hong KS, et al; Valsartan Efficacy oN modesT blood pressUre REduction in acute ischemic stroke (VENTURE) study group. Modest blood pressure reduction with valsartan in acute ischemic stroke: a prospective, randomized, open-label, blindedend-point trial. Int J Stroke 2015;10(05):745-751

56 Lee M, Ovbiagele B, Hong KS, et al. Effect of blood pressure lowering in early ischemic stroke: meta-analysis. Stroke 2015; 46(07):1883-1889

57 Michinaga S, Koyama Y. Pathogenesis of brain edema and investigation into anti-edema drugs. Int J Mol Sci 2015;16(05): 9949-9975

58 Yamaguchi S, Kobayashi S, Yamashita K, Kitani M. Pial arterial pressure contribution to early ischemic brain edema. J Cereb Blood Flow Metab 1989;9(05):597-602

59 Vemmos KN, Tsivgoulis G, Spengos K, et al. Association between 24-h blood pressure monitoring variables and brain oedema in patients with hyperacute stroke. J Hypertens 2003;21(11): 2167-2173

60 Skalidi SJ, Manios ED, Stamatelopoulos KS, et al. Brain edema formation is associated with the time rate of blood pressure variation in acute stroke patients. Blood Press Monit 2013;18 (04):203-207

61 Stone JA, Willey JZ, Keyrouz S, et al. Therapies for hemorrhagic transformation in acute ischemic stroke. Curr Treat Options Neurol 2017;19(01):1

62 de Courten-Myers GM, Kleinholz M, Holm P, et al. Hemorrhagic infarct conversion in experimental stroke. Ann Emerg Med 1992; 21(02):120-126

63 Liu K, Yan S, Zhang S, Guo Y, Lou M. Systolic blood pressure variability is associated with severe hemorrhagic transformation in the early stage after thrombolysis. Transl Stroke Res 2016; 7(03):186-191

64 Beretta S, Versace A, Carone D, et al. Cerebral collateral therapeutics in acute ischemic stroke: a randomized preclinical trial of four modulation strategies. J Cereb Blood Flow Metab 2017;37 (10):3344-3354

65 Marzan AS, Hungerbühler HJ, Studer A, Baumgartner RW, Georgiadis $\mathrm{D}$. Feasibility and safety of norepinephrine-induced arterial hypertension in acute ischemic stroke. Neurology 2004;62(07): 1193-1195

66 Rordorf G, Koroshetz WJ, Ezzeddine MA, Segal AZ, Buonanno FS A pilot study of drug-induced hypertension for treatment of acute stroke. Neurology 2001;56(09):1210-1213

67 Schwarz S, Georgiadis D, Aschoff A, Schwab S. Effects of induced hypertension on intracranial pressure and flow velocities of the middle cerebral arteries in patients with large hemispheric stroke. Stroke 2002;33(04):998-1004 
68 Ko SB, Choi HA, Lee K. Clinical syndromes and management of intracerebral hemorrhage. Curr Atheroscler Rep 2012;14(04): 307-313

69 Brott T, Broderick J, Kothari R, et al. Early hemorrhage growth in patients with intracerebral hemorrhage. Stroke 1997;28(01):1-5

70 Qureshi AI, Mohammad YM, Yahia AM, et al. A prospective multicenter study to evaluate the feasibility and safety of aggressive antihypertensive treatment in patients with acute intracerebral hemorrhage. J Intensive Care Med 2005;20(01): 34-42

71 Terayama Y, Tanahashi N, Fukuuchi Y, Gotoh F. Prognostic value of admission blood pressure in patients with intracerebral hemorrhage. Keio Cooperative Stroke Study. Stroke 1997;28 (06):1185-1188

72 Powers WJ, Zazulia AR, Videen TO, et al. Autoregulation of cerebral blood flow surrounding acute (6 to 22 hours) intracerebral hemorrhage. Neurology 2001;57(01):18-24
73 Butcher KS, Jeerakathil T, Hill M, et al; ICH ADAPT Investigators. The intracerebral hemorrhage acutely decreasing arterial pressure trial. Stroke 2013;44(03):620-626

74 Anderson CS, Heeley E, Huang Y, et al; INTERACT2 Investigators. Rapid blood-pressure lowering in patients with acute intracerebral hemorrhage. N Engl J Med 2013;368(25):2355-2365

75 Anderson CS, Huang Y, Wang JG, et al; INTERACT Investigators. Intensive blood pressure reduction in acute cerebral haemorrhage trial (INTERACT): a randomised pilot trial. Lancet Neurol 2008;7(05):391-399

76 Antihypertensive Treatment of Acute Cerebral Hemorrhage (ATACH) investigators. Antihypertensive treatment of acute cerebral hemorrhage. Crit Care Med 2010;38(02):637-648

77 Qureshi AI, Palesch YY, Barsan WG, et al; ATACH-2 Trial Investigators and the Neurological Emergency Treatment Trials Network Intensive blood-pressure lowering in patients with acute cerebral hemorrhage. N Engl J Med 2016;375(11):1033-1043 